\title{
ACADV: An Automatized Concept for Advancement in Farming
}

\author{
Dilip Singh", Anushka Sehrawat ${ }^{2}$, Ankit Kumar Singh ${ }^{3}$, Er. Chandan Prasad ${ }^{4}$ \\ B. Tech Scholar, CTIS, School of Information \& Technology, Pune, India ${ }^{1,2,3}$ \\ Assistant Professor, IT, Ajeenkya DY Patil University, Pune, India 4
}

\begin{abstract}
Agriculture plays a very crucial role in Indian economy. Over centuries, the growth of agriculture contributed to the rise of civilizations. This research paper covers major challenges faced by farmers in India. It includes involvement of automated farming. Although, the contribution of agriculture to GDP is one sixth, it provides employment opportunities to the needy. This research is about focusing on farmer reducing his human efforts in farming due lack of facility as well as due natural disasters. The proposed idea would ensure surely development and agriculture growth by considering various factors such as focusing on attributes of soil, temperature, moisture, automated dripping system, pesticide, automated fertilizer suggestion, decision making on these fact for proper growth of seed, having WSN positioned in all over farm and drone which is able to do various things. The entire proposed system will be available at minimum cost including drone which is able to work in air and land. Taking into consideration various factors, famers will get best support in agriculture to get better outcome in both food and money. In other words, real development in terms of growth shared by all sections of population has not taken place. Here is where, this automated agriculture comes into picture.
\end{abstract}

Keywords: Agriculture, WSN, Drone, Soil Sensor, Moisture Sensor, Temperature Sensor, IR-Sensor, Obstacle Sensor, Chemical Sensor, Wind Sensor, Water Actuator Sensor, Server, Data Mining, Automated Decision Making and Microcontroller.

\section{INTRODUCTION}

Agriculture can be called as a "state subject" under the constitution of India. History and development agriculture has been around millenniums. It has been around since the beginning of time and has undergone significant development since the time of earliest cultivations. Most people do not think highly of the famer and agriculture in general. After all, there is no "visible connection" between rural and urban life. To develop this connection, farming would now be connected to IOT and embedded systems which would in turn reduce the efforts of the farmer.

In this world of technology, it is also necessary to introduce technology in the most important part of lifeagriculture. Imagine a warm summer day and you have to go out on farm to do agriculture-even giving it a single thought also seems to be so tiresome. So, thinking of all the efforts which the farmer has to put in to grow vegetables, we gave this automated farming a shot. Under these circumstances, the farmer would get all the information related to his farm on his mobile. Information includes everything related to farming-pesticides, fertilizers, seeds, sprinkling water, need of more fertilizers, pesticides everything.

In the current environment we need a system which is able to analyses all the attributes which are necessary for farming such as WSN, Drone, Soil Sensor, Moisture Sensor, Temperature Sensor, IR-Sensor, Obstacle Sensor,
Chemical Sensor, Wind Sensor, Water Actuator Sensor and Micro-Controller.

\section{LITERATURE REVIEW}

Before the start of the project we had shepherded the following investigation on different things.

That are as follows:

- Biodynamic Agriculture:

It comes under organic farming category which treats farms as individual organisms, balancing the holistic development and interrelationship of the soil, plants, and animals as a self-nourishing system without external inputs insofar.

- Extensive Farming:

It is also called as extensive agriculture. It signifies the production system that uses small inputs of labour, fertilizers, and capital relative to the land area being farmed.

\section{- Factory Farming:}

It refers to the procedure of raising livestock in bounding at high stocking density, where a farm is operated as a factory. 
- Free Range:

It is the term denoted to the method of animal husbandry where the animals are permitted to roam freely instead of being confined in any manner.

- Industrial Agriculture:

It is the form of urban farming which comes in from the industrialized production of livestock, poultry fish and crops. This technique is economic, techno scientific and political. They include creativity in agricultural machinery and farming methods and much more.

- Intensive Farming:

It includes usage of technologies such as pesticides and chemical fertilizers relative to land area.

- Organic Farming:

It is the form of agriculture which dependson methods such as crop rotation, greenmanure, compost and biological pest control to uphold soil creativity. It strictly limits the use of manufactured fertilizers, pesticides, plant growth regulators such as hormones, livestock antibiotics, food additives, and genetically modified organism.

- Sustainable Agriculture:

Sustainable agriculture is the practice of farming using principles of ecology, the study of relationship between organisms and their environment. It has been defined as an integrated system of plant and animals production practice having a site specific application that will last over the long term.

- Urban Agriculture:

Urban agriculture is the practice of cultivating, processing and distributing food in, or around, a village, town or city.Urban agriculture in accumulation can also involve animal husbandry, aquaculture, agro-forestry and horticulture.

The chemicals widely used for wheat is urea which is a highly leaching fertilizer. Two third or half of nitrogen should be applied during sowing.

\section{A. A Crop Monitoring System Based on Wireless Sensor Network}

Wireless Sensor Network crop monitoring application is useful to farmer for exactness agriculture. The application monitors the entire farm from remote location by means of IOT (Internet of Things). Application works on sensor network and two types of nodes. Energy saving algorithm is used in node to protect energy [1]

System having two nodes sensor node which accumulate all environmental and soil parameters value soil moisture, temperature, air, humidity, light, etc. and second node involve of cam to capture images and observer crops. Crop monitoring claim consists of two sensor node image sensor and environment parameter collector. These two sensors accumulate the information about crops. Image sensor gather crop growth, height and second sensor node collect data about humidity, soil condition, etc. and this data is collected at base station and then get transmission to internet (web application). Data analysis is get done at server side.

B. Automatic Drip Irrigation System using Wireless Sensor Network and Data Mining Algorithm

Data mining algorithm are used to take pronouncements on drip irrigation system. Automated drip irrigation system having WSN positioned in all over farm and different type of sensors like soil moisture sensor, wind direction, wind speed, soiltemperature gives reading to control station and base station [2].

WSN uses ad hoc network which gives self-configuration and tractability. Sensor data is given to base station and data is acknowledged using ZigBee. Data processing is done at base station for decision making. Data mining algorithm is used to take conclusion on data from sensor to drip. All observation are remotely monitor through web application. Data mining Naïve Bayes algorithm is used for decision making on data set which is real time feed from field sensor. Algorithm check possibility of each characteristic. Drip irrigation on and off decision are made. Previous data set of agriculture is provided to take decision. All data of field is known to web application for observation [3].

C. Wireless sensor network with irrigation valve control. Wireless sensor network with valve control unit is established with actuator hardware and software. Irrigation is regulator by actuator. Web application is used for manual control and plan irrigation timing. Water meter specify the requirement of water. Node unit comprise soil moisture sensor and actuator.

Two way communications take place from actuator to node and base station. Packet with control commands are sent between node and actuator. Actuator control solenoid valve depending upon water meter value and scheduling timing for water supply. Water necessity for different crop is different also depends on other feature like soil type, temperature, etc. This system measures only soil moisture parameter to take irrigation decision [4]

D. Wireless sensor network infrastructure for agriculture. Existing WSNs that monitor agriculture structure measures different soil parameter and environment conditions. This WSN is composed of node with software and hardware units. Node has control unit which control sensors and communicate with base station. At mega and ARM are frequently used as control unit. ZigBee, Bluetooth, Wi-Fi used for transceiver in WSN. Network report soil value, volumetric water contains, landscape movement, earthquakes and volcano information. 


\section{ISO 3297:2007 Certified}

Vol. 5, Issue 3, March 2017

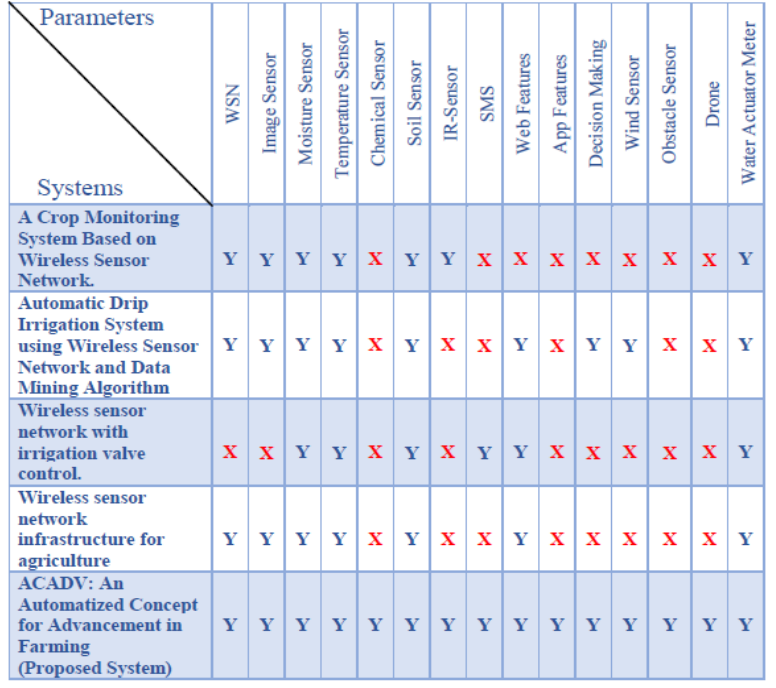

Fig. 1. Taxonomy Chart

\section{PROPOSED SYSTEM}

We proposes a novel system which is a composition of IoT and Embedded system "ACADV: An Automatized Concept for Advancement in Farming". In the proposed system with the help of data mining algorithm we able to take the decision on the selected features.ACADV an approach in which we are focusing on attributes of soil, temperature, moisture, automated dripping system, pesticide, automated fertilizer suggestion, decision making on these fact for proper growth of seed, having WSN positioned in all over farm and drone which is able to do various things. We are going to use sensors are:

- Temperature Sensor

- Moisture Sensor

- IR Sensor (INFRA-RED)

- Soil Sensor

- Obstacle Sensor (Ultra-Sonic)

- Chemical Sensor

- Micro- Controller

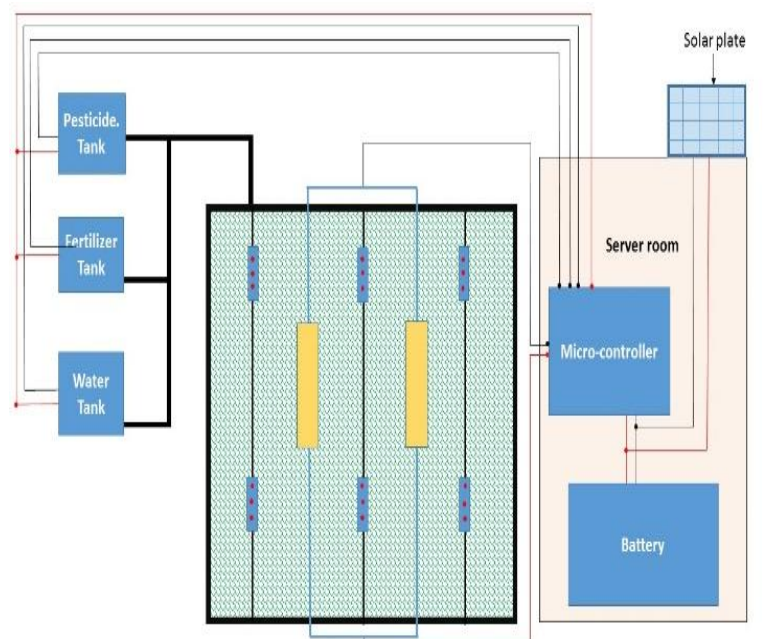

Fig. 2. Propose Farming Layout

\section{A. Temperature Sensor}

A temperature sensor extent the hotness or coolness of an object. The sensor functioning base is the voltage that's recite across the diode. The temperature upswings whenever the voltage rises. The sensor registers any voltage drop between the transistor base and emitter. This sensor gives the analysis of the temperature at a field.

\section{B. Moisture Sensor}

The soil moisture sensor uses capacitance to extent dielectric permittivity of the surrounding medium. In soil, dielectric permittivity is a function of the water content. The sensor creates a voltage proportionality to the dielectric permittivity, and therefore the water content of the soil. This sensor is used to measure the water content present in the soil.

\section{IR Sensor (INFRA-RED)}

This sensor is used to detect the insects / unwanted things in the crop. The basic principle of this sensor is, it is operated upon infra-red light. The intensity of infra-red is constantly falls upon a IR-Sensor, when insect/unwanted thing comes in contact with this light then the connection between light and sensor get disconnected and at that time sensor get triggered. Hence, it detects that there is insect or unwanted things present on crop.

\section{Soil Sensor}

It measure the volumetric composition of organic components present in the soil. Based upon volumetric composition it detects the type of soil present in the field.

\section{E. Obstacle Sensor (Ultra-Sonic)}

The basic principle of this sensor is, it works on sound waves and their reflection property. It has two parts; ultrasonic transmitter and ultra-sonic receiver. Transmitter transmits the sound wave and receiver receives the reflected wave on its reception, it sends the electrical signal to the microcontroller. As the speed of light is $3 \times 108 \mathrm{~m} / \mathrm{s}$. Hence, time required to receive back the transmitted sound wave is the distance of obstacle is calculated. The ultra-sonic sensor allows the drone to detect and avoid obstacles and also to measure the distance from the obstacle.

\section{F. Chemical Sensor}

A chemical sensor is used to detect the amount of chemical substance present in pesticides dissolved in the soil. According to the amount of chemical composition present in the soil, it transmit the data to the microcontroller and further that information is processed by microcontroller.

\section{G. Micro- Controller}

A microcontroller is a small computer on a single integrated circuit. Nowadays it is manufactured in the form of Nano-chips. Microcontroller is used for making the things automated such as remote control robots, appliances, power tools, embedded devices etc. 


\section{IV.CONCLUSION}

By implementing "ACADV: An Automatized Concept for Advancement in Farming", we can improve the traditional way of agriculture irrigation system in different region of India. The system will improve the topology assembly to make all nodes converse with each other, also to improve the stability of wireless sensors in communication by better software and hardware design. Especially, it is a step towards digitalization and smart irrigation control system based on IoT network and Embedded Device with the ability to make decision by real-time humidity data and expert data.

\section{REFERENCES}

[1] Sankar, P., Norman, S.R,(2009) "Embedded System for Monitoring Atmosphere is Weather Conditions Using Weather Balloon", International Conference on Control, Automation, Communication and Energy Conservation 2009, pp 1-4.

[2] Mahesh M.Galgalikar,(2010)"Real-Time Automization Of Agricultural Environment for Social Modernization of Indian Agricultural System", on IEEE Proceedings,pp 20-23.

[3] L.L.Pfitscher, (2011) "An automated irrigation system for rise cropping with remote supervision"- proceeding of international conference on power engineering, energy and electrical devices, vol. 50, pp 90.

[4] Vasif Ahmed, Siddharth A. Ladhake,(2010) "Design of Ultra Low Cost Cell Phone Based Embedded System for Irrigation", on International Conference on Machine Vision and Human Machine Interface, vol.20,pp 40-45. 